\title{
Romiplostim and Eltrombopag in Immune Thrombocytopenia as a Second-Line Treatment
}

\author{
Erjola Bidika ${ }^{1}$, Hafsa Fayyaz ${ }^{2}$, Marina Salib ${ }^{2}$, Areeba N. Memon ${ }^{2}$, Asavari S. Gowda ${ }^{3}$, Bhavana
} Rallabhandi $^{4}$, Ivan Cancarevic ${ }^{2}$

1. Internal Medicine, California Institute of Behavorial Neurosciences \& Psychology, Fairfield, USA 2. Internal Medicine, California Institute of Behavioral Neurosciences \& Psychology, Fairfield, USA 3. Medicine, California Institute of Behavioral Neurosciences \& Psychology, Fairfield, USA 4. Neurology, California Institute of Behavioral Neurosciences \& Psychology, Fairfield, USA

Corresponding author: Erjola Bidika, erjolabidika@gmail.com

\begin{abstract}
Immune thrombocytopenia (ITP) is an autoimmune disorder characterized by platelet count less than $100 \times 10^{9} / \mathrm{L}$ and an increased risk of bleeding. The risk of bleeding increases in proportion with the degree of thrombocytopenia. Although several medications are used for primary thrombocytopenia treatment, refractoriness remains a concern. Romiplostim and eltrombopag, two relatively new drugs, have been shown to be successful in ITP treatment after standard treatment failure. The current guidelines recommend their use as a second-line treatment. In this article, we have tried to compare which of these two medications is the best option considering clinical effectiveness, cost-effectiveness, adverse effects, and the possibility of switching between them in case of ineffectiveness. The studies used in this article were found in the PubMed database. All the studies are limited to adults. Based on these studies, both medications seem to be a largely effective, safe option. Romiplostim appears to have slightly fewer adverse effects and higher costs. Switching between thrombopoietin receptor agonists (TRAs) is a successful way to overcome adverse effects and inadequacy according to the currently available literature. We believe that more detailed studies are needed to determine which of these drugs should be considered the first choice, to report long term efficacy and adverse effects, and to determine if treatment guidelines can change regarding the use of TRAs as first-line treatment.
\end{abstract}

Categories: Internal Medicine, Hematology

Keywords: romiplostim, eltrombopag, immune thrombocytopenia, platelets, thrombopoietin, thrombopoietin receptor agonists, itp

\section{Introduction And Background}

Immune thrombocytopenia (ITP) is a condition of low platelet count (less than 100×109/L), in which platelets are destroyed by the immune system, with an estimated incidence of 2-4/100000 adults/year [1,2]. In this disorder, platelet production and survival are altered by antibodies, mainly IgGs that attack glycoproteins, GP IIb/IIIa, GP Ib/IX, GP Ia/IIa, and other glycoproteins expressed on megakaryocytes and platelets [3]. Platelets are phagocytosed and destroyed prematurely by the reticuloendothelial system, particularly the spleen. In these patients, the risk of bleeding increases in proportion with the degree of thrombocytopenia [1]. In ITP patients, long term risks, morbidity, and mortality rate RR 2.3 (95\% CI, 1.8-3.0) are increased compared to the general population [4].

Bidika et al. This is an open access article distributed under the terms of the Creative Commons Attribution License CC-BY 4.0., which permits unrestricted use, distribution, and reproduction in any medium, provided the original author and source are credited.

ITP is characterized as primary and secondary, according to the etiology [5]. Primary ITP is defined as isolated thrombocytopenia without other causes [5]. Secondary ITP is defined as any other form of thrombocytopenia except for primary and includes thrombocytopenia secondary to an underlying disease such as hepatitis $\mathrm{C}$ infection, systemic lupus erythematosus, or lymphoproliferative disorders [5]. ITP is further categorized as newly diagnosed ( $<3$ months), persistent (3-12 months), and chronic ( $>12$ months) [5]. In children, this disorder is often self-limited, but most adults need treatment [6]. First-line treatment includes IV immunoglobulin, steroids, anti-D-immunoglobulin, and lastly, splenectomy [7]. Rituximab is an alternative treatment in patients who are at increased risk of bleeding after the failure of one of the above treatments [7]. Refractoriness to the previously mentioned therapies led to new treatment strategies.

Hematologist Endre Kelemen discovered thrombopoietin (TPO) and determined its role in platelet stimulation in 1958. TPO was able to be purified by five laboratories almost simultaneously in $1994[8,9]$. TPO is a hormone consisting of 332 amino acids, synthesized primarily in the liver, which binds to TPO receptors referred to as c-MpL on the megakaryocytic surface [10]. Recombinant human thrombopoietin (rhTPO) and pegylated recombinant human megakaryocyte growth and development factor (PEG-rhMGDF), were found to increase platelet counts, but their development was discontinued after antibodies that crossreacted with endogenous TPO were found in healthy volunteers causing paradoxical thrombocytopenia $[11,12]$. Shortly after this, thrombopoietin receptor agonists (TRAs) were introduced as a promising treatment. TRAs mimic endogenous TPO by activating intracellular signaling pathways such as Janus 
kinase/signal transducer and activator of transcription (JAK/STAT) and mitogen-activated protein kinase (MAPK) and enhancing platelet count by stimulating megakaryocytes [13,14].

In 2008 US Food and Drug Administration (FDA) approved two TRAs, romiplostim and eltrombopag, based on the results of the phase- 3 trial published in The Lancet [15]. Both drugs are approved in the treatment of ITP in patients who relapse after splenectomy or who have a contraindication to splenectomy, in those who are at increased risk of bleeding or following the failure of at least one other therapy [7]. Romiplostim and eltrombopag have no sequence homology with TPO, thus decreasing the risk of antibody formation [16]. Both drugs bind to the TPO receptor (c-MpL) and stimulate megakaryocyte differentiation and proliferation [16]. Romiplostim is a recombinant, Fc-peptide fusion protein (peptibody) given subcutaneously, while eltrombopag is an orally available drug that binds to the transmembrane region of c-MpL [17]. Recognizing that ITP pathophysiology is defined as increased destruction of platelets and decreased production, the treatment should also not be limited to focusing only on diminishing platelet destruction, but also increasing survival [18]. Therefore, the use of romiplostim and eltrombopag in ITP treatment is supported by promoting megakaryocyte survival and increasing platelet production [18]. In this review article, we will review and compare the effectiveness and side effects of romiplostim and eltrombopag in ITP treatment and the validation of switching between these two drugs, based on previously published studies.

\section{Review}

\section{Romiplostim and eltrombopag clinical response}

The normal platelet count in the general population ranges between 150 and $400 \times 10^{9} / \mathrm{L}$ while in ITP patients treated with TRAs, the main treatment goal is to decrease the risk of bleeding and maintain platelet count between $50 \times 10^{9} / \mathrm{L}$ and $150 \times 10^{9} / \mathrm{L}$ [18]. However, in patients with a severe disease without bleeding, a platelet count of $\geqslant 20 \times 10^{9} / \mathrm{L}$ is tolerable [18]. Several studies have been done to compare the outcomes in patients treated with romiplostim to patients treated with standard treatment or placebo. Kuter et al.

studied 157 patients with pretreatment platelet counts $50 \times 10^{9} / \mathrm{L}$ or less, who were treated with romiplostim in a 52-week study [19]. They found a significant increase in platelet counts, a lower rate of treatment failure, a lower rate of splenectomy and bleeding, and a significant improvement in life quality [19]. In a 24week long study Kuter et al. analyzed 83 patients treated with romiplostim from whom $50 \%$ splenectomized and with a pretreatment platelet count $30 \times 10^{9} / \mathrm{L}$ or less [15]. They reported increased platelet counts in $79 \%$ of splenectomized patients and $88 \%$ in non-splenectomized patients [15]. They also reported the ability to reduce the use of other ITP medications [15]. Bussel et al. studied 41 patients for six weeks [20]. The platelet counts were reported to be increased to $50 \times 10^{9} / \mathrm{L}$ or more [20]. Shirasugi et al. analyzed the outcomes in 22 Japanese patients treated with romiplostim in a 12-week study, with a pretreatment platelet count of $30 \times 10^{9} / \mathrm{L}$ or less and $44 \%$ of whom had been splenectomized [21]. They reported a platelet response in $95 \%$ of the patients and a reduced need for rescue therapy (only in nine percent of patients) [21]. Several studies have been made to assess the effectiveness of eltrombopag. Cheng et al. studied 135 patients from 23 different countries treated with eltrombopag in a three-phase, 24-week study [22]. Pretreatment platelet counts in these patients were $30 \times 10^{9} / \mathrm{L}$ or less, and the splenectomy rate $36 \%$ [22]. They reported increased platelet counts in $79 \%$ of patients and a reduced need for rescue therapy or other ITP medications [22]. Bussel et al. studied 118 patients who had a refractory or relapsed ITP in a six-week study [23]. Their pretreatment platelet counts were less than $30 \times 10^{9} / \mathrm{L}$, and $47 \%$ had undergone splenectomy [23]. A significant increase in platelet counts and a decrease in bleeding were reported in $80 \%$ of patients treated with eltrombopag by the end of the second week [23]. Yang et al. analyzed in an eight-week study the response of treatment with eltrombopag in 104 Chinese patients [24]. 51.9\% of the patients had pretreatment platelet counts less than $15 \times 10^{9} / \mathrm{L}$, and $17.3 \%$ had undergone splenectomy [24]. A significant response was reported in $57.7 \%$ of patients after six weeks of treatment with eltrombopag [24]. Bussel et al. studied 76 patients from 23 countries in a six-week study [25]. Patients had pretreatment platelet counts less than $30 \times 10^{9} / \mathrm{L}$, and $39 \%$ were splenectomized [25]. They reported a significant response with increased platelet counts in $59 \%$ of patients treated with eltrombopag [25]. Tomiyama et al. studied 15 Japanese patients in a six-week study, with platelet counts less than $30 \times 10^{9} / \mathrm{L}$ and from whom $69 \%$ were splenectomized [26]. They reported a response to treatment in $60 \%$ of patients, decreased bleeding, and a lower eltrombopag dose to be effective in Japanese patients [26]. The included studies can be found in Table 


\section{Cureus}

\begin{tabular}{|c|c|c|c|c|c|c|}
\hline $\begin{array}{l}\text { Number of } \\
\text { patients }\end{array}$ & Study,year & Country & Splenectomized & $\begin{array}{l}\text { Pretreatment platelet } \\
\text { counts }\end{array}$ & $\begin{array}{l}\text { Platelet } \\
\text { response }\end{array}$ & $\begin{array}{l}\text { Study } \\
\text { duration }\end{array}$ \\
\hline \multicolumn{7}{|c|}{ ROMIPLOSTIM } \\
\hline 157 & Kuter et al., 2010 [19] & $\begin{array}{l}\text { USA, Europe, } \\
\text { Australia }\end{array}$ & $0 \%$ & $<50 \times 10^{9} / \mathrm{L}$ & $\geqslant 50 \times 10^{9} / \mathrm{L}$ & 52 weeks \\
\hline 83 & Kuter et al., 2008 [15] & USA, Europe & $50 \%$ & $<30 \times 10^{9} / \mathrm{L}$ & $\geqslant 50 \times 10^{9} / \mathrm{L}$ & 24 weeks \\
\hline 41 & $\begin{array}{l}\text { Bussel et al., } 2006 \\
\text { [20] }\end{array}$ & USA & $67 \%$ & - & $\geqslant 50 \times 10^{9} / \mathrm{L}$ & 6 weeks \\
\hline 22 & $\begin{array}{l}\text { Shirasugi et al., } 2011 \\
\text { [21] }\end{array}$ & Japan & $44 \%$ & $<30 \times 10^{9} / \mathrm{L}$ & $\geqslant 50 \times 10^{9} / \mathrm{L}$ & 12 weeks \\
\hline \multicolumn{7}{|c|}{ ELTROMBOPAG } \\
\hline 135 & $\begin{array}{l}\text { Cheng et al., } 2011 \\
\text { [22] }\end{array}$ & 23 countries & $36 \%$ & $<30 \times 10^{9} / \mathrm{L}$ & $\geqslant 50 \times 10^{9} / \mathrm{L}$ & 24 weeks \\
\hline 118 & $\begin{array}{l}\text { Bussel et al., } 2007 \\
\text { [23] }\end{array}$ & USA & $47 \%$ & $<30 \times 10^{9} / L$ & $\geqslant 50 \times 10^{9} / \mathrm{L}$ & 6 weeks \\
\hline 104 & Yang et al., 2017 [24] & China & $17.3 \%$ & $\begin{array}{l}51.9 \% \text { of patients }< \\
15 \times 10^{9} / \mathrm{L}\end{array}$ & $\geqslant 50 \times 10^{9} / \mathrm{L}$ & 8 weeks \\
\hline 76 & $\begin{array}{l}\text { Bussel et al., } 2009 \\
\text { [25] }\end{array}$ & 23 countries & $39 \%$ & $<30 \times 10^{9} / \mathrm{L}$ & $\geqslant 50 \times 10^{9} / \mathrm{L}$ & 6 weeks \\
\hline 15 & $\begin{array}{l}\text { Tomiyama et al., } \\
2012 \text { [26] }\end{array}$ & Japan & $69 \%$ & $<30 \times 10^{9} / \mathrm{L}$ & $\geqslant 50 \times 10^{9} / \mathrm{L}$ & 6 weeks \\
\hline
\end{tabular}

TABLE 1: Characteristics of Reviewed Studies

Overall, 303 patients treated with romiplostim were included in these studies, with an average of $75 \%$ showing a significant response in platelet counts. Four of the patients were reported to have post-treatment worsening thrombocytopenia. Three patients reported to have platelet counts exceeding $450 \times 10^{9} / \mathrm{L}$ and two patients had extended response after the period of treatment. The number of patients treated with eltrombopag in these studies overall was 448 , where 313 of them (69\%) responded to the treatment. These findings can be found in Figure 1 and Figure 2. Treatment with both romiplostim and eltrombopag resulted in significantly higher platelet counts response than placebo. The clinical response was higher than that of the other second-line treatment agents. A significant decrease of hemorrhagic episodes was also reported. In some studies, the efficacy of eltrombopag resulted in being dose-dependent. In another study, the starting efficacy dose of eltrombopag was lower in East Asian patients. Considering the high response of ITP patients treated with romiplostim and eltrombopag, these two agents seem to be a precious treatment in refractory cases. 


\section{Cureus}

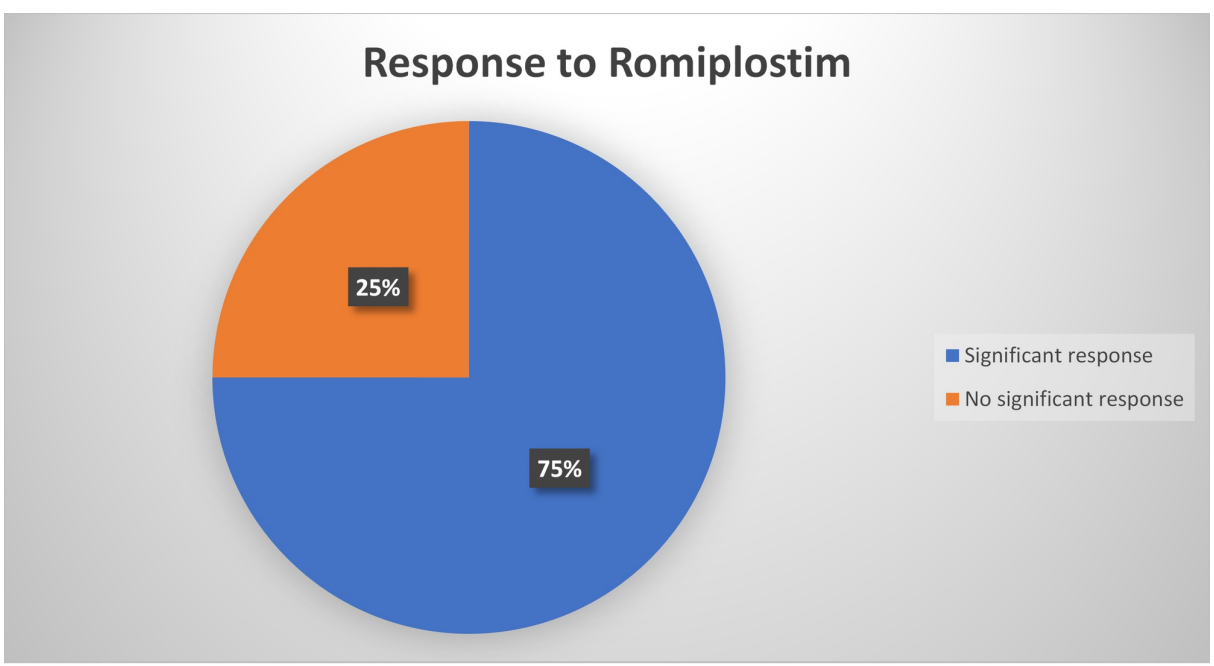

FIGURE 1: Response to Treatment With Romiplostim

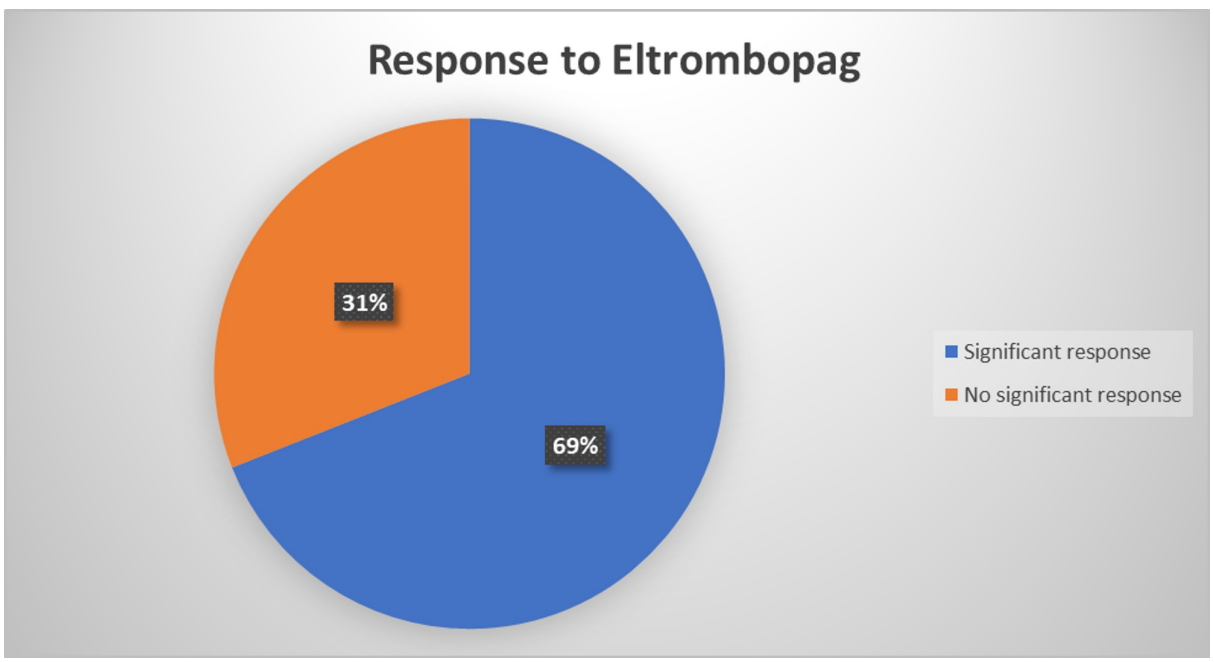

FIGURE 2: Response to Treatment With Eltrombopag

\section{Adverse effects of romiplostim and eltrombopag}

Multiple studies have concluded that romiplostim and eltrombopag are generally well-tolerated medications $[19,27,28]$. However, some adverse effects have been reported. Shirasugi et al. reported that the most common adverse effects experienced by patients treated with romiplostim were headache, back pain, extremity pain, nasopharyngitis, and peripheral edema [21]. Myalgia, headache, dizziness, insomnia, and arthralgia were also reported in patients treated with romiplostim [19]. One patient reportedly experienced a multiorgan failure, which resolved after romiplostim discontinuation [29]. Cheng et al. found that among 135 patients treated with eltrombopag, three had episodes of thromboembolic events, nine patients had a mild increase of ALT levels, and five patients had an increase in total bilirubin [22]. Among 104 patients treated with eltrombopag, Bussel et al. reported hypokalemia in 11 patients, increased ALT in nine patients, and nasopharyngitis in 11 patients. Only in four patients were severe adverse effects reported [23]. The EXTEND and the RAISE studies reported mostly mild to moderate adverse effects in patients treated with eltrombopag [30]. Fewer serious adverse effects were reported [30]. Mild to moderate adverse effects include nausea, dizziness, headache, and muscle aches [30]. Severe adverse effects include rebound thrombocytopenia, stroke, myocardial infarction, cataracts, and vascular occlusions [30]. Although the EXTEND study demonstrated an increase in alanine aminotransferase (ALT) up to three times the upper limit in $10 \%$ of patients, ALT levels returned to normal even when patients continued the treatment or when they discontinued it. Further, this study demonstrated that indirect bilirubin was increased, suggesting that the liver injury was not serious [31].

Kim et al. analyzed 18 patients and reported that seven patients on eltrombopag showed abnormal 
hepatobiliary laboratory values [31]. However, ALT levels returned to normal after treatment discontinuation [31]. One of the patients showed bone marrow fibrosis after the first year of treatment with eltrombopag [31]. A systematic review and meta-analysis of randomized controlled trials suggested an increased risk of thromboembolic events in the patients treated with TRAs compared with placebo or standard care [32]. Long-term observational studies in patients treated with TRAs suggested that a minority of them developed bone marrow fibrosis [33,34]. However, it was found to be reversible and dose-dependent [33,34]. Moulis et al. concluded that the risk of gastrointestinal adverse effects is higher with eltrombopag. However, hematological adverse effects are higher with romiplostim, and no significant difference is noted between them, according to thrombosis [35]. Loffredo and Violi also reported an increased risk of thromboembolic events in patients treated with eltrombopag and who had a chronic liver disease [36].

Although adverse effects have been reported in multiple studies, they seemed to be mild and reversible after drug discontinuation. Most of the adverse effects reported seem not to be a significant concern, but adverse effects such as abnormal liver function tests require continuous monitoring so that the treatment can be modified accordingly. Liver function test abnormalities are mainly seen in patients treated with eltrombopag, and no significant changes are reported in patients on romiplostim. Neither of these two agents is associated with significantly increased rates of severe adverse effects. However, cases of bone marrow fibrosis and thromboembolic events have been reported with both drugs. It is especially important to perform a detailed evaluation of thrombosis risk and whether it is due to the inflammation in ITP itself or due to treatment with TRAs. Overall, long-term treatment with romiplostim and eltrombopag is considered a largely safe and well-tolerated option with romiplostim showing a slight dominance.

\section{Switching between TRAs}

Lack of effectiveness refers to a lack of platelet count response to prior treatment, or an inability to maintain stable platelet counts [37]. These are reported as the main reasons for therapy switching [37]. Patient preference is another reason, with pre-dominance to eltrombopag switch (32\%) compared to romiplostim (22\%) [37]. Kuter et al. reported platelet counts to rise from mean $41.0 \times 10^{9} / \mathrm{L}$ to $138 \times 10^{9} / \mathrm{L}$ with romiplostim and from $43.4 \times 10^{9} / \mathrm{L}$ to $120 \times 10^{9} / \mathrm{L}$ with eltrombopag [37]. They suggested that changing between TRAs may be appropriate in patients who fail to respond to the initial TRA used [37]. González-Porras et al. reported a $75 \%$ response in patients who switched between TRAs [38]. Better outcomes were reported in patients where the reason for switching was adverse effects or patient preference than in ineffectiveness to prior TRA [38]. Even though 16 patients responded to treatment with romiplostim, they requested switching to eltrombopag due to the convenience of taking the drug orally [38]. Depré et al. summarized the outcomes of published studies and reported that in patients who switched to romiplostim due to treatment ineffectiveness, $73 \%$ responded positively. All patients who switched to romiplostim due to adverse effects responded positively [29]. Of patients who switched from romiplostim to eltrombopag due to treatment ineffectiveness, 58\% responded positively. Of those who switched due to platelet counts fluctuations, $71 \%$ responded positively [29]. Of those who switched due to adverse effects, $92 \%$ responded positively, and in patients who switched due to patient preference, $100 \%$ responded positively [29]. They observed that adverse effects were decreased from 27 to nine in patients who switched from eltrombopag to romiplostim and increased from 12 to 19 in patients who switched from romiplostim to eltrombopag [29]. Several other studies suggest that switching between TRAs is appropriate in case of the ineffectiveness of the prior agent [17,24].

The above studies support the switching between TRAs as an effective way to overcome treatment resistance and adverse effects. An increase in platelet response rate was achieved in the majority of cases. Switching due to treatment resistance seems unsuccessful compared to switching due to the adverse effects or platelet level fluctuations. Switching to romiplostim appears to be more effective. On the other hand, switching to eltrombopag appears to be more concerning regarding increased adverse effects.

\section{Cost-effectiveness}

Considering the high cost of TRAs, research has been done to estimate the overall cost of these drugs. Allen et al. analyzed the cost between patients treated with romiplostim and eltrombopag in England and Wales and concluded that eltrombopag is cost-effective compared to romiplostim. Eltrombopag was found to be $£ 40,261$ (\$50,501) less expensive in every non-splenectomized ITP patient during their lifetime and £88,904 $(\$ 111,516)$ less expensive in every splenectomized ITP patient [39]. Tremblay et al. analyzed the cost of TRAs for patients treated in the USA [40]. According to this study the overall cost for eltrombopag is approximately $\$ 66,560$ ( $\$ 65,998$ in splenectomized patients and $\$ 67,151$ in non-splenectomized patients) and for romiplostim $\$ 91,039$ (\$91,485 in splenectomized patients and $\$ 91,455$ in non-splenectomized patients) [40]. Fust et al. concluded that romiplostim is cost-effective related to eltrombopag with a slight difference [41]. Al-Samkari reported a romiplostim cost of $\$ 2165.34$ per $250 \mu \mathrm{g}$ vial or $\$ 4330.68$ per $500 \mu \mathrm{g}$ vial [17]. For eltrombopag, a cost of $\$ 182.46$ per $12.5 \mathrm{mg}$ or $25 \mathrm{mg}$ tablet, $\$ 330.20$ per $50 \mathrm{mg}$ tablet, and $\$ 495.30$ per $75 \mathrm{mg}$ tablet was reported [17].

While both drugs have high overall cost, in England, eltrombopag is more cost-effective than romiplostim. In the USA, the studies oppose each other, but based on the cost per eltrombopag tablet and romiplostim vial, we conclude that romiplostim cost is higher. 


\section{Conclusions}

ITP treatment after first-line therapy failure remains a challenge for clinicians. The introduction of TRAs romiplostim and eltrombopag was a significant step for refractory ITP treatment. Several studies in the last decade have shown promising results, however long-term efficacy and adverse effects seem unclear. Overall, both drugs have proved to be a reasonable treatment option in increasing platelet count and survival. Adverse effects appear to be mostly mild and reversible with drug discontinuation. Switching between TRAs remains a good option, and both drugs have a high cost. Long term studies would be of significant help in determining long term severe adverse effects and long-term efficacy. Currently, we recommend TRAs use for refractory ITP treatment, especially in the setting of limited options. Further studies should be done to assess TRAs use as a first-line treatment.

\section{Additional Information \\ Disclosures}

Conflicts of interest: In compliance with the ICMJE uniform disclosure form, all authors declare the following: Payment/services info: All authors have declared that no financial support was received from any organization for the submitted work. Financial relationships: All authors have declared that they have no financial relationships at present or within the previous three years with any organizations that might have an interest in the submitted work. Other relationships: All authors have declared that there are no other relationships or activities that could appear to have influenced the submitted work.

\section{References}

1. Kistangari G, McCrae KR: Immune thrombocytopenia. Hematol Oncol Clin North Am. 2013, 27:495-520. 10.1016/i.hoc.2013.03.001

2. Lambert MP, Gernsheimer TB: Clinical updates in adult immune thrombocytopenia. Blood. 2017, 129:28292835. 10.1182/blood-2017-03-754119

3. McMillan R, Tani P, Millard F, Berchtold P, Renshaw L, Woods VL: Platelet-associated and plasma antiglycoprotein autoantibodies in chronic ITP. Blood. 1987, 70:1040-1045.

4. Nørgaard M, Jensen AØ, Engebjerg MC, et al.: Long-term clinical outcomes of patients with primary chronic immune thrombocytopenia: a Danish population-based cohort study. Blood. 2011, 117:3514-3520. 10.1182/blood-2010-10-312819

5. Rodeghiero F, Stasi R, Gernsheimer T, et al.: Standardization of terminology, definitions and outcome criteria in immune thrombocytopenic purpura of adults and children: report from an international working group. Blood. 2009, 113:2386-2393. 10.1182/blood-2008-07-162503

6. Kühne T: Diagnosis and management of immune thrombocytopenia in childhood . Hamostaseologie. 2017, 37:36-44. 10.5482/HAMO-16-06-0017

7. Neunert C, Lim W, Crowther M, et al.: The American Society of Hematology 2011 evidence-based practice guideline for immune thrombocytopenia. Blood. 2011, 117:4190-4207. 10.1182/blood-2010-08-302984

8. Kelemen E, Cserhati I, Tanos B: Demonstration and some properties of human thrombopoietin in thrombocythaemic sera. Acta Haematol. 1958, 20:350-355. 10.1159/000205503

9. Kuter DJ: Milestones in understanding platelet production: a historical overview . Br J Haematol. 2014, 165:248-258. 10.1111/bjh.12781

10. Hitchcock IS, Kaushansky K: Thrombopoietin from beginning to end. Br J Haematol. 2014, 165:259-268. 10.1111/bjh.12772

11. Kim TO, Despotovic J, Lambert MP: Eltrombopag for use in children with immune thrombocytopenia . Blood Adv. 2018, 2:454-461. 10.1182/bloodadvances.2017010660

12. Molineux G, Newland A: Development of romiplostim for the treatment of patients with chronic immune thrombocytopenia: from bench to bedside. Br J Haematol. 2010, 150:9-20. 10.1111/j.1365-2141.2010.08140.x

13. Mitchell WB, Pinheiro MP, Boulad N, et al.: Effect of thrombopoietin receptor agonists on the apoptotic profile of platelets in patients with chronic immune thrombocytopenia. Am J Hematol. 2014, 89:228-234. 10.1002/ajh.23832

14. Nomura S: Advances in diagnosis and treatments for immune thrombocytopenia . Clin Med Insights Blood Disord. 2016, 9:15-22. 10.4137/CMBD.S39643

15. Kuter DJ, Bussel JB, Lyons RM, et al.: Efficacy of romiplostim in patients with chronic immune thrombocytopenic purpura: a double-blind randomised controlled trial. Lancet. 2008, 371:395-403. 10.1016/S0140-6736(08)60203-2

16. Wörmann B: Clinical indications for thrombopoietin and thrombopoietin-receptor agonists. Transfus Med Hemother. 2013, 40:319-325. 10.1159/000355006

17. Al-Samkari H, Kuter DJ: Optimal use of thrombopoietin receptor agonists in immune thrombocytopenia . Ther Adv Hematol. 2019, 10:2040620719841735-2019. 10.1177/2040620719841735

18. Onisâi M, Vlădăreanu AM, Spînu A, Găman M, Bumbea H: Idiopathic thrombocytopenic purpura (ITP) - new era for an old disease. Rom J Intern Med. 2019, 57:273-283. 10.2478/rjim-2019-0014

19. Kuter DJ, Rummel M, Boccia R, et al.: Romiplostim or standard of care in patients with immune thrombocytopenia. N Engl J Med. 2010, 363:1889-1899. 10.1056/NEJMoa1002625

20. Bussel JB, Kuter DJ, George JN, et al.: AMG 531, a thrombopoiesis-stimulating protein, for chronic ITP [published correction]. N Engl J Med. 2006, 2054:1672-1681. 10.1056/NEJMoa054626

21. Shirasugi Y, Ando K, Miyazaki K, et al.: Romiplostim for the treatment of chronic immune thrombocytopenia in adult Japanese patients: a double-blind, randomized Phase III clinical trial. Int J Hematol. 2011, 94:71-80. 10.1007/s12185-011-0886-8

22. Cheng G, Saleh MN, Marcher C, et al.: Eltrombopag for management of chronic immune thrombocytopenia 
(RAISE): a 6-month, randomised, phase 3 study [published correction]. Lancet. 2011, 382:393-402. 10.1016/S0140-6736(10)60959-2

23. Bussel JB, Cheng G, Saleh MN, et al.: Eltrombopag for the treatment of chronic idiopathic thrombocytopenic purpura. N Engl J Med. 2007, 357:2237-2247. 10.1056/NEJMoa073275

24. Yang R, Li J, Jin J, et al.: Multicentre, randomised phase III study of the efficacy and safety of eltrombopag in Chinese patients with chronic immune thrombocytopenia. Br J Haematol. 2017, 176:101-110. 10.1111/bjh. 14380

25. Bussel JB, Provan D, Shamsi T, et al.: Effect of eltrombopag on platelet counts and bleeding during treatment of chronic idiopathic thrombocytopenic purpura: a randomised, double-blind, placebo-controlled trial. Lancet. 2009, 373:641-648. 10.1016/S0140-6736(09)60402-5

26. Tomiyama Y, Miyakawa Y, Okamoto S, et al.: A lower starting dose of eltrombopag is efficacious in Japanese patients with previously treated chronic immune thrombocytopenia. J Thromb Haemost. 2012, 10:799-806. 10.1111/j.1538-7836.2012.04695.x

27. Ptushkin VV, Vinogradova OY, Pankrashkina MM, Chernikov MV, Arshanskaya EG, Tkachenko NE: Thrombopoietin receptor agonists in the treatment of chronic resistant primary immune thrombocytopenia: efficacy and safety data in real clinical practice. Ter Arkh. 2018, 90:70-76. 10.26442/terarkh201890770-76

28. Saleh MN, Bussel JB, Cheng G, et al.: Safety and efficacy of eltrombopag for treatment of chronic immune thrombocytopenia: results of the long-term, open-label EXTEND study. Blood. 2013, 121:537-545. 10.1182/blood-2012-04-425512

29. Depré F, Aboud N, Mayer B, Salama A: Bidirectional inefficacy or intolerability of thrombopoietin receptor agonists: new data and a concise review. Blood Transfus. 2018, 16:307-312. 10.2450/2017.0258-16

30. Cheng G: Eltrombopag, a thrombopoietin- receptor agonist in the treatment of adult chronic immune thrombocytopenia: a review of the efficacy and safety profile. Ther Adv Hematol. 2012, 3:155-164. $10.1177 / 2040620712442525$

31. Kim YK, Lee SS, Jeong SH, et al.: Efficacy and safety of eltrombopag in adult refractory immune thrombocytopenia. Blood Res. 2015, 50:19-25. 10.5045/br.2015.50.1.19

32. Catalá-López F, Corrales I, de la Fuente-Honrubia C, et al.: Risk of thromboembolism with thrombopoietin receptor agonists in adult patients with thrombocytopenia: Systematic review and meta-analysis of randomized controlled trials. Med Clin (Barc). 2015, 145:511-519. 10.1016/j.medcli.2015.03.014

33. Steurer M, Quittet P, Papadaki HA, et al.: A large observational study of patients with primary immune thrombocytopenia receiving romiplostim in European clinical practice. Eur J Haematol. 2017, 98:112-120. 10.1111/ejh.12807

34. Wong RSM, Saleh MN, Khelif A, et al.: Safety and efficacy of long-term treatment of chronic/persistent ITP with eltrombopag: final results of the EXTEND study [published correction]. Blood. 2018, 8:709-2017. 10.1182/blood-2017-04-748707

35. Moulis G, Bagheri H, Sailler L, et al.: Are adverse drug reaction patterns different between romiplostim and eltrombopag? 2009-2013 French PharmacoVigilance assessment. Eur J Intern Med. 2014, 25:777-780. 10.1016/j.ejim.2014.09.006

36. Loffredo L, Violi F: Thrombopoietin receptor agonists and risk of portal vein thrombosis in patients with liver disease and thrombocytopenia: a meta-analysis. Dig Liver Dis. 2019, 51:24-27. 10.1016/j.dld.2018.06.005

37. Kuter DJ, Macahilig C, Grotzinger KM, et al.: Treatment patterns and clinical outcomes in patients with chronic immune thrombocytopenia (ITP) switched to eltrombopag or romiplostim. Int J Hematol. 2015, 101:255-263. 10.1007/s12185-014-1731-7

38. González-Porras JR, Godeau B, Carpenedo M: Switching thrombopoietin receptor agonist treatments in patients with primary immune thrombocytopenia. Ther Adv Hematol. 2019, 10:2040620719837906-2019. 10.1177/2040620719837906

39. Allen R, Bryden P, Grotzinger KM, Stapelkamp C, Woods B: Cost-effectiveness of eltrombopag versus romiplostim for the treatment of chronic immune thrombocytopenia in England and Wales. Value Health. 2016, 19:614-622. 10.1016/j.jval.2016.03.1856

40. Tremblay G, Dolph M, Bhor M, Said Q, Elliott B, Briggs A: Cost-consequence model comparing eltrombopag versus romiplostim for adult patients with chronic immune thrombocytopenia. Clinicoecon Outcomes Res. 2018:705-713. 10.2147/CEOR.S177324

41. Fust K, Parthan A, Li X, et al.: Cost per response analysis of strategies for chronic immune thrombocytopenia. Am J Manag Care. 2018, 24:294-302. 